\title{
On Project Oriented Problem Based Learning (POPBL) for a First Year Engineering Circuits Project
}

\author{
Séamus McLoone, Bob Lawlor and Andrew Meehan
}

\author{
The Callan Institute, Department of Electronic Engineering, \\ National University of Ireland Maynooth, Maynooth, Co. Kildare, Ireland \\ Email: \{seamus.mcloone; bob.lawlor; andrew.meehan\} @eeng.nuim.ie
}

\begin{abstract}
This paper describes a pilot study on incorporating a Project-Oriented Problem Based Learning (POPBL) educational model into a first year engineering degree programme, in the form of a circuits-based project. While many variations of PBL exist, our pilot model is closely aligned to the Aalborg PBL model. This paper describes how the traditional first year Bachelor of Engineering (BE) programme at the National University of Ireland Maynooth (NUIM) was modified to accommodate the POPBL model. It outlines the key features of the approach taken and presents a detailed evaluation of the pilot study. Both staff and students responded favourably to the adopted learning style. This paper also highlights the lessons learned from the implementation of the POPBL model.
\end{abstract}

Keywords - Project-Oriented Problem Based Learning, Student-centred Learning, Peer learning

\section{INTRODUCTION}

The concept of problem based learning (PBL) offers a significant alternative learning paradigm to the conventional lecture-based approach. The many benefits of PBL are well documented in the research literature. These include improving active learning, encouraging a deeper approach to learning, improving self-directed learning, improving the consideration of interdisciplinary knowledge, developing a professional identity, developing responsibility and improving various process competencies such as project management, collaboration, teamwork, conflict resolution and communications skills [1 - 7].

Despite the wide variation in PBL models [1], there still exists some common pedagogical principles to all variations, as follows:

- Problem-based - the starting point of the learning process is the consideration of a problem, preferably a real problem as this can be more motivating to the students than an artificial problem.

- Self-directed - students are given freedom to orient and formulate the problem specification as well as directing the development of a solution.

- Experiential learning - students are required to build on their previous experience and interests.
- Activity-based - students are actively engaged in research, decision-making, writing etc.

- Interdisciplinary - the solution to the problem should typically span traditional subject boundaries.

- Exemplary practice - depending on the nature of the particular problem, students may not be guaranteed to achieve all of the documented learning outcomes associated with a particular subject module. This short-coming, however, is offset by the fact that the students are instead 'learning-to-learn' and as such will be better equipped in the future to 'fill in' subject-specific content gaps.

- Group-based - peer-learning is facilitated and encouraged as this is also central to the effective development of communication and team-work skills.

Since its foundation in 1974, the University of Aalborg in Denmark has developed a world-wide reputation as a centre of excellence in problem and project based learning, particularly in the disciplines of Engineering and Science [8]. This educational model is widely known as the Aalborg PBL model and is founded on problem-based project work. Here, the project is an integral part of the education model and hence the Project-Oriented Problem Based Learning (POPBL) model. 
In Aalborg, each semester of a degree programme has the same basic structure. We focused on their $\mathrm{BSc}$ in Electronics and IT degree as this is closely related to our Electronic Engineering degree offering. The project forms the focal point of a semester, and is typically worth 30 ECTS. The project itself takes up half of this, i.e. 15ECTs. In the current version of the Aalborg model, the project is strongly supported by 7.5 ECTS of traditionally taught modules. The remaining 7.5 ECTS consists of other modules which are core to the degree programme but not necessarily directly relevant to the project, such as fundamental mathematics or basic computer programming, for example. Each semester of the programme usually has a different thematic project, such as electronics, circuits, analogue, control, etc.

Collaborative learning (or peer-learning) is also a central element of the Aalborg model and the projects are always undertaken in small groups. The group size tends to vary from $6-8$ students in first year to $1-2$ students in final year.

In this paper, we look at adopting a first year POPBL model in the form of a circuits-based project. We align our pilot project with the Aalborg PBL model insofar as resources and infrastructure allow. Our pilot project took place in semester 2 of our first year Bachelor of Engineering in Electronic Engineering degree programme at NUI Maynooth. At the end of the semester, the students were surveyed for their feedback on this new style of learning (for them). Both staff and students were also given the opportunity to express their thoughts and opinions through special focus groups. The results from this evaluation process showed significant support for the POPBL educational model.

The rest of the paper is structured as follows. Section II outlines the actual implementation of the pilot POPBL circuits-based project in NUI Maynooth. Section III documents the evaluation process and presents a summary of the key feedback. Section IV highlights the lessons learned from the pilot study. The paper concludes with some suggestions for future work in section $\mathrm{V}$.

\section{IMPLEMENTATION OF PBL PROJECT}

The first year Electronic Engineering programme in NUI Maynooth previously consisted of twelve 5 ECTS modules, split over two semesters, as outlined in Table 1. For the pilot study, it was decided to remove modules EE105 Professional Skills and EE107 Engineering Design and replace these with a 10 ECTS Circuits project, as presented in Table 2. This project would form a significant component of semester 2 and would be supported by several conventionally taught modules, namely EE101 Electronic Engineering Fundamentals, EE103 Digital Systems 1 and EE111 Electric Circuits.

Table 1 - Pre-POPBL Year 1

\begin{tabular}{|l|}
\multicolumn{1}{|c|}{ Year 1 - Semester 1 } \\
EE101 Electronic Engineering Fundamentals \\
CS141 Introduction to Programming \\
EE103 Digital Systems 1 \\
EE104 Physics for Engineers 1 \\
EE105 Professional Skills \\
EE106 Engineering Mathematics 1 \\
\hline \multicolumn{1}{|c|}{ Year 1 - Semester 2 } \\
EE107 Engineering Design \\
EE108 Computing for Engineers \\
EE109 Electronic Materials Science \\
EE110 Physics for Engineers 2 \\
EE111 Electric Circuits \\
EE112 Engineering Mathematics 2
\end{tabular}

Table 2 - Incorporating POPBL into Year 1

\begin{tabular}{|l|}
\hline \multicolumn{1}{|c|}{ Year 1 - Semester 1 } \\
EE101 Electronic Engineering Fundamentals \\
CS141 Introduction to Programming \\
EE103 Digital Systems 1 \\
EE104 Physics for Engineers 1 \\
EE106 Engineering Mathematics 1 \\
EE109 Electronic Materials Science \\
\hline \multicolumn{1}{c|}{ Year 1 - Semester 2 } \\
EE108 Computing for Engineers \\
EE110 Physics for Engineers 2 \\
EE111 Electric Circuits \\
EE112 Engineering Mathematics 2 \\
EE199 Electronic Circuits Project (10 ECTS) \\
\hline
\end{tabular}

The rationale for removing the modules EE105 and EE107 was that by engaging in a substantial group project the students would have the opportunity to experientially develop their design and professional skills (e.g. technical writing and presentation) as well as their team-work skills, thus covering the important components of the removed modules. In addition, the staff members associated with EE105 and EE107 acted, coincidently as it turned out, as facilitators of the project. Hence the overall structure of the first year programme and the staffing resource issue remained largely unchanged. 
One side effect of these changes, however, was that the EE109 Electronic Material Science module had to be moved back to semester 1 .

In the Aalborg model, the supporting taught modules would be in the same semester as the project and would be delivered upfront in the first few weeks of the semester. The project would run in parallel, but the majority of this work would occur in the later weeks once the taught modules had been completed. This was not a luxury afforded to us our current infrastructure would not support this upfront demand on teaching, particularly as several of our modules are taught by other departments within the university. In an effort to minimise disruption to our standard setup, the project was purposely placed in semester 2 so that the main support modules (EE101 and EE103) could be delivered in their entirety in the first semester.

\section{a) Deliverables \& Assessment}

There were three main deliverables required from each team for their PBL project. These were a set of reflective journals worth $10 \%$, an interim report (with presentation and interview) worth $20 \%$ and the main final report (with presentation and interview) worth $70 \%$. The reflective journals included both individual and team-based contributions. In addition to each of the reports, teams also had to make a presentation on their work (all team members had to contribute) and finally defend their work via interview. It is important to state that the interviews involved assessing the individual student as opposed to the overall team.

Although a team produced a single report, team members were nevertheless effectively assessed individually. A student's grade was determined based on the team's report and their individual ability to answer questions during the interview.

\section{b) Timeline \& Workshops}

As part of the Pilot PBL module, the students were given a detailed timeline incorporating all of the various deliverables, as in Fig. 1. It was felt that this was important to allow the students to see an overall picture of key milestones.

In addition, five specific workshops were given to the students. These consisted of:

- Workshop 1 - PBL \& Group work

- Workshop 2 - Engineering design fundamentals

- Workshop 3 - Engineering ethics

- Workshop 4 - Technical report writing

- Workshop 5 - Presentation skills

The workshops typically consisted of some lecture time and discussion time and were front loaded at the start of the semester.

All of this information was placed in electronic format onto the Moodle system for students to access at any stage. The Moodle system was also where teams submitted their various deliverables.

It should also be noted that the group formation was done in the first week. The project tasks were given to each of the groups at the end of week 1 and they started the actual project task at the start of week 2 .

As Fig. 1 shows, the deliverables were spaced as evenly as possible over the course of the semester to the extent that the final interviews and presentations were held after the standard end-of-semester exam period, to allow the students adequate time for preparation.

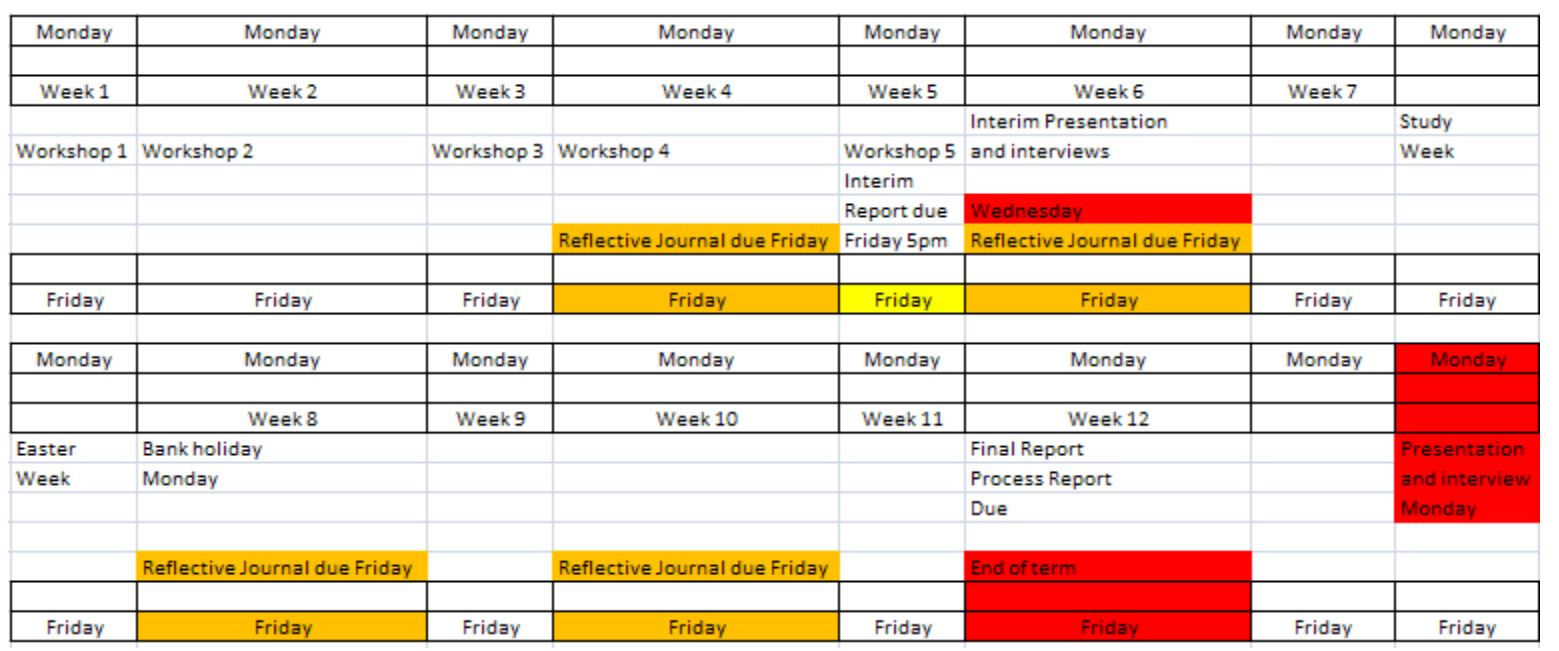

Figure 1 - Timeline for Pilot PBLProject 


\section{c) Team Selection}

For this particular pilot study, we followed the Aalborg PBL model and allowed students to self select their teams. The first year class consisted of 18 students initially and it was agreed at the start to have a maximum of 3 groups. The self selection process resulted in 3 quite different groups and contained 7, 6 and 5 team members respectively. One student eventually left the programme and the final group sizes were 7, 5 and 5. Each of the groups, once formed, were randomly given a project specification.

\section{d) Project Specifications}

The three projects specifications were short and relatively open-ended to give the teams as much scope as possible for research and exploration - in effect, we wanted the students to drive their project, to take ownership of it. The only conditions imposed on all projects were that it had to involve using circuits, as this was the theme of the PBL module, and that the use of microprocessors was strictly prohibited. The latter restriction simply ensured the need for circuit design and analysis.

The three projects for this pilot consisted of the design and implementation of a Christmas decoration, a crossroads traffic lights system and a 'Tin Can Alley' shooting game.

\section{e) Facilitation}

The role of the staff in PBL is to act as facilitators to each of the teams, with the aim of encouraging and supporting the students in their work but without directly involving themselves in that work. In the Aalborg model, the teams are entirely responsible for all aspects of the project, including organizing meetings with the facilitator, booking suitable meeting rooms, writing agendas, etc. In cases where this does not happen, the facilitator will not, in general, intervene or try to arrange a meeting for the team.

As this was the first time that this POPBL approach was piloted within the department, we took a slightly different approach to the Aalborg model. We decided that for the first 5 weeks we would require the teams to meet with their assigned facilitator at least once a week, regardless of what progress they had achieved. At the end of week 5 we adopted a more laissez-faire approach to facilitation and encouraged the students to take more control of the direction and management of their project.

\section{EVALUATION OF PBL PROJECT}

A number of evaluation instruments were used to analyze the pilot module. These included:

- A student focus group hosted by an independent PBL expert.

- A staff focus group also hosted by an independent PBL expert.

- A detailed end-of-semester student survey which included significant quantitative and qualitative feedback data.

Table 3 shows the average and standard deviation of the ratings given by the students' for a range of statements, as shown. These statements focused on three key aspects of PBL, namely the learning experience, the facilitation and the physical resources. Students were asked to rate each statement on a scale of 1 (strongly disagree) to 5 (strongly agree).

Table 3 - POPBL evaluation results. 1 to 5 represents strongly disagree, disagree, not sure, agree and strongly agree respectively.

\begin{tabular}{lcc}
\hline \multicolumn{1}{c}{ Statement } & $\begin{array}{c}\text { Average } \\
\text { rating (1-5) }\end{array}$ & $\begin{array}{c}\text { Std. } \\
\text { dev. }\end{array}$ \\
\hline $\begin{array}{l}\text { PBL is an effective method of } \\
\text { learning for me }\end{array}$ & 4.18 & 0.64 \\
\hline PBL prepares me for my exams. & 3.35 & 0.79 \\
\hline $\begin{array}{l}\text { PBL prepares me for my future } \\
\text { professional life. }\end{array}$ & 4.41 & 0.62 \\
$\begin{array}{l}\text { PBL improves my teamwork } \\
\text { skills. }\end{array}$ & 4.29 & 0.99 \\
$\begin{array}{l}\text { PBL improves my written } \\
\text { communication skills. }\end{array}$ & 4.00 & 0.71 \\
$\begin{array}{l}\text { PBL improves my presentation } \\
\text { skills. }\end{array}$ & 4.41 & 0.51 \\
$\begin{array}{l}\text { PBL has motivated me to learn. } \\
\text { I had good access to my } \\
\text { facilitator. }\end{array}$ & 4.00 & 0.87 \\
\hline $\begin{array}{l}\text { I made good use of the access } \\
\text { to my facilitator. }\end{array}$ & 3.88 & 0.70 \\
\hline $\begin{array}{l}\text { I have no difficulty in } \\
\text { questioning my facilitator. }\end{array}$ & 3.88 & 0.49 \\
$\begin{array}{l}\text { I am happy with the amount } \\
\text { and type of feedback provided } \\
\text { by my facilitator. }\end{array}$ & 3.47 & 0.94 \\
$\begin{array}{l}\text { The physical environment is } \\
\text { suitable for me to participate in } \\
\text { PBL (eg. room, furniture, etc.) }\end{array}$ & 4.41 & 0.51 \\
$\begin{array}{l}\text { There were adequate resources } \\
\text { (software and hardware) } \\
\text { available for your project work. }\end{array}$ & 4.35 & 0.60 \\
\hline
\end{tabular}


The feedback from the students is very positive towards PBL. It is interesting to note that most students found the PBL to be an effective learning experience and motivated them to learn. This was also evident in talking with the students who generally conveyed enthusiasm and excitement when discussing their relevant team project. There were one or two students who did not enjoy the PBL experience and openly admitted that they struggled with the team environment, preferring instead to work on their own.

While expected, it is worth noting that the students also identified the benefits of the PBL model as a means for improving their communication, presentation and general teamwork skills.

In terms of the qualitative student feedback and also that obtained from the focus group with the independent expert, there were some very insightful comments to support the above data. One student noted that " $P B L$ worked really well in the sense that it encourages student to be more liberated in terms of learning". Another student stated that they "liked working as part of a team". It was something that they had "never done before and found to be quite interesting”.

The students clearly had an issue with the facilitation process and, although, the majority of them felt that they had good and open access with their facilitators, there were some that clearly did not. Examining the raw data (not presented here) showed that the main problem lay with the students making use of their facilitator's support -7 of the 17 students reported that they did not make good use of their facilitator's time. This is likely an issue associated with a new learning style. The students were not familiar with the POPBL approach and therefore the concept of facilitation and, in particular, how to make good use of the facilitator was almost alien to them. This is re-enforced by the fact that the same students are used to having a teacher stand at the top of the class and directing them in what to do.

Some students also identified communication as an issue for them stating that they felt that "the communication side of PBL was difficult. It was hard to communicate with everyone and even with the facilitators as we could be waiting a few days for a reply from an email". Other students noted that "some of the team mates did not work and therefore put the team under pressure".

From the staff (i.e. the facilitators) viewpoint, it was a different, but richly rewarding and enjoyable experience. They also found the students to be significantly more motivated about their work. They found reading and examining the final reports to be more interesting than the standard repetitive lab reports of conventionally taught modules. This was simply due to the fact that the PBL reports tended to contain new material and information that would not be found in a typical lab report. The peer learning within the teams was another reported positive aspect of the PBL model - it was great to see groups of students working together as a team. The facilitators also noted that the idea of facilitating as opposed to teaching was difficult to get used to at the start and noted that "not being able to get involved with the team and taking direction of the project was challenging at times".

Overall, both facilitators and students found the new style of learning through PBL was a worthwhile model and were keen to see the learning process across later years of the $\mathrm{BE}$ in Electronic Engineering degree programme.

\section{LESSONS LEARNED}

On final review of the pilot, the facilitators noted a number of important operational aspects that would have improved the pilot PBL project for the students. Some of these issues were also raised by the students. Two of the main lessons learned were related to group selection and dissemination of information.

\section{a) Team selection}

As mentioned previously, the pilot PBL implementation allowed the students to self select their own groups (akin to the Aalborg PBL model). However, this resulted in three very different groups, one of which was referred to as the 'leftover' group. As the term suggests, this group consisted of those students that did not turn up on the day the team formation took place and also the perceived weaker students in the class. One of the other groups consisted mainly of a group of friends, which is understandable. However, this latter selection does not necessarily equip the team with the necessary skill set for completing a team project.

In this pilot, the 'leftover' group has significant problems including poor communication, poor teamwork, multiple conflicts with no real resolution, and ultimately failed their project as a result. The biggest issue with this group lay with the fact that several of the students simply did not engage and, in fact, some had not even turned up for the first few weeks while the project was meant to be well under way. This problem does not seem to be an issue in the Aalborg model but this can likely be attributed to two important contextual differences.

Firstly, the average age of incoming Irish university students is 18 years with some as young as 17 
whereas the corresponding figure in Denmark (and much of mainland Europe) is around 19 years. Thus, Irish students, on average, tend to be less mature than their European counterparts. Furthermore, in Ireland, incoming university students have very little prior experience of group project work whereas the Danish primary and secondary education systems involve significant group-work components.

Alternative group selection techniques will be considered in future implementations of the PBL model. These include random selection, a combination of self and staff-assigned selection and selection based on project preference. For now, this remains a topic for future work.

\section{b) Dissemination of Information}

As this was the first time that the PBL model was delivered in the Department of Electronic Engineering, there were several teething issues with the implementation. The main practical concern that became apparent during the PBL project was the lack of information available upfront to the students. In the pilot, everything was presented on an asneeded basis. Facilitators and/or students would identify needs on an ongoing basis and, subsequently, react to those needs shortly thereafter. However, most of these needs related to material that could, and should, have been available upfront to the students at the start of their project. Examples included templates for the reflective journals, templates for the reports and, more importantly, a student handbook outlining the PBL concept, how facilitation works, information on teamwork and general good practice tips.

\section{CONCLUSIONS \& FUTURE WORK}

This paper has presented the implementation and evaluation of a pilot POPBL educational model in the form of a significant Circuits project in a first year Electronic Engineering programme. The project was worth 10 ECTS and was directly supported by three different traditionally taught 5 ECTS modules.

The evaluation process involved surveying the students and conducting focus groups with both staff and students. Overall, the students responded in favour of the learning experience associated with the PBL approach and requested for an increase of such activity in their degree programme. They found the experience quite different, challenging but enjoyable and worthwhile at the end. It certainly improved many of their process competencies such as teamwork, leadership, communication, research, time management, project management and, in some cases, conflict resolution.

The staff, who acted as facilitators, also found the experience enjoyable and rewarding and certainly felt that their students were significantly more motivated when it came to the PBL project.

Future work involves evaluation a second iteration of the POPBL circuits-based project. In addition, the integration of a PBL project in Year 2 of the BE programme will be investigated.

\section{ACKNOWLEDGEMENTS}

We would like to thank the Centre for Teaching and Learning, NUIM for their support with this project and Prof Lars Peter Jensen, from Aalborg University, for his advice and guidance throughout the pilot study.

\section{REFERENCES}

[1] E. Graaff and A. Kolmos, "Characteristics of Problem-Based Learning," International Journal of Engineering Education, vol. 19, no. 5, pp. 657-662, 2003.

[2] J. Biggs, Teaching for Quality Learning at University, ( $2^{\text {nd }}$ edition), Buckingham: SRHE/Open University Press, 2003.

[3] E. Graaff, and R. Cowdroy, "Theory and Practice of Educational Innovation through Introduction of Problem Based Learning in Architecture," International Journal of Engineering Education, Vol 13, No.3, pp. 166-174, 1997.

[4] C. Hmelo and D. Evensen, Introduction. In: Problem-based Learning - a Research Perspective on Learning Interactions, Evensen, D. \& Hmelo, C. (eds), p1-18. Lawrence Erlbaum Associates Publications, London, 2000.

[5] A. Kolmos, "Reflection on Project Work and Problem-based Learning," European Journal of Engineering Education, Vol. 21, No.2, pp. 141-148, 1996

[6] M. Savin-Baden, Problem-based Learning in Higher Education: Untold Stories, The society for Research into Higher Education \& Open University Press, Berkshire, 2000.

[7] M. Savin-Baden, Facilitating Problem-based Learning: Illuminating Perspectives, The society for Research into Higher Education \& Open University Press, Berkshire, 2003.

[8] F. Kjersdam, and S. Enemark, The Aalborg Experiment: Project Innovation in University Education, Aalborg: Aalborg University Press, 1994. 